\title{
GEOGRAPHY OF THINGS BASED FLOOD RISK INSURANCE MODELLING
}

\author{
Popov, S.; Popovic, L.\#; Cosic, D.; Novakovic, T. \& Curcic, K. \\ University of Novi Sad, Faculty of Technical Sciences, Trg Dositeja Obradovica 6, Novi Sad, Serbia \\ E-Mail: 1jiljana.popovic@uns.ac.rs $\left({ }^{\#}\right.$ Corresponding author)
}

\begin{abstract}
The systems for managing urban and suburban areas are increasingly becoming data producers and subsequently data consumers. There are several possible approaches to integrated management and exception handling in these areas. One of the approaches is the Smart City concept using the Geography of Things (GoT) technological framework. In this paper, we offer a GoT based model for the assessment of risk which is suitable for financing, a model which is best suited for risk management and which contributes to the Smart City concept. The proposed model is based on combining the social community, built environment, Internet of Things sensor systems, series of the existing data, public utilities and economic services, and potential hazard in the spatial context of the modern Smart Community. The final output of the proposed model is the information about the price of risk of the endangered area, which is necessary for further decision-making and Smart City management.

(Received in March 2020, accepted in May 2020. This paper was with the authors 1 month for 2 revisions.)
\end{abstract}

Key Words: Geography of Things, Geographic Information System, Smart City, Flood, Insurance Modelling, Urbanisation

\section{INTRODUCTION}

All migrations within a country and across borders are towards cities. According to the United Nations, the share of the population living in urban areas globally has been rising rapidly since the second half of the last century: while 30 percent of the world's population was urban in 1950, this share rose to 55 percent in 2018 [1]. The UN projections to 2050 indicate that the urbanisation process will continue in all countries. The most rapid urbanisation among Global North countries is expected in lower-middle-income countries, including the Republic of Serbia.

Urbanisation is a complex socioeconomic process that transforms the built environment, converting formerly rural settlements into urban ones, while also shifting the spatial distribution of population from rural to urban areas [1]. If the increase in urban population is seen through the prism of decline in rural population, according to the UN the decline in the rural population of Serbia will amount to at least $30 \%$ between 2018 and 2050.

Sustainable urbanisation in the sense of sustainable cities and communities implies inclusive and sustainable urbanisation and capacity for participatory, integrated and sustainable human settlement planning and management [2]. In other words, making cities resilient and smart.

Although suburban areas that emerged as a result of unplanned urbanisation pose an almost insoluble problem in cities, the availability of information technologies in developed countries offers a wider perspective in dealing with urban problems and enables integrated risk management. The use of geoinformatics opens up different possibilities in handling spatial problems and choosing the most acceptable model. The urban environment, where the acquisition of data related to citizens, their assets and infrastructure of living and coexistence is made possible, is today viewed as the "Smart City" context model [3].

Smart Cities promote a sustainable lifestyle [4]. Infrastructure, innovation and technology are the components that make Smart Cities efficient and self-sufficient [4]. The concept of 
Smart City construction has centered on next-generation technologies such as the Internet of Things (IoT), i.e. [5-8], and cloud computing has become a new model for future urban development [5].

Smart City concept as a part of modern urbanisation is defined also as a model of new urbanisation based on the $4^{\text {th }}$ industrial revolution and application of new generation technologies of Industry 4.0 for the purpose of planning, construction, management, integrated industrialisation, informatisation, modernisation and sustainable development of modern cities [9]. The term of Industry 4.0 became known in 2011 when an idea was promoted aiming towards the enhancement of competitiveness of the German manufacturing industry and technological innovation leadership [9, 10], while other zones of the globe adopted their own projects, focusing on technological innovations [10]. Internet of Things, Internet of Services and Internet of Energy can be considered as an element that can create a connection between the Smart City Initiative and Industry 4.0. [11] which encloses several technological concepts, such as interoperability among different systems [10].

Information models and infrastructure come into use faster than other infrastructure systems. However contradictory it may sound, it is easier to establish IoT mechanisms in suburban zones than completely urbanise half rural and partly urbanised areas. Actually, these zones have been created as a result of spatial distribution of desired resources, i.e., due to the common spatial concept of highly urbanised environment and not so well-built rural areas. If urban areas are observed within the Smart City framework, with fast implementation of concepts such as IoT and Safe City, adding to this the spatial context of the highly urban area and the suburban area, the conclusion is self-evident. The technical and technological context of solving the problem of flood risk insurance modelling should be sought within a model relying on the Geography of Things (GoT) concept of technology, social community and space. The system of data acquisition, data management and data usage in the context of IoT and Geographic Information System (GIS) brings a new interpretation of data. It supports multidimensional spatial and spatially based data. Data sources are heterogeneous and anachronistic, based on individual measurement or collected as a series in real time or offline [3]. As such, the data form an excellent basis for simulation of different scenarios of hazardous events upon which it is possible to decide on acceptable measures for risk management and also decide whether certain investments have been justified or not. The use of modern simulation techniques in risk analysis supports the long-term success of a project [12].

\section{STUDY AREA}

Urban development of an area is influenced by three factors: natural population increase, immigration and expansion of cities.

From the aspect of urbanisation in the province of Vojvodina, the dominance of the city of Novi Sad is easily noticed. The emergence of peri-urban areas around cities, particularly around Novi Sad, poses a great problem. The specific evolution of villages in the immediate vicinity of big cities is a result of the later urbanisation phase, i.e., the secondary urbanisation phase. Here, a city becomes a significant factor for the development of nearby villages through its own development. These villages are usually called peri-urban settlements.

The overlap of urban and rural activities leads to spatial conflicts and devastation of land, i.e., land conversion. With the emergence of peri-urban areas, agricultural land of high quality is being devastated and converted into residential areas and industrial complexes. Such devastation can frequently be seen in nature reserves such as the National Park of Fruska Gora, or along the banks of the river Danube in Novi Sad. 
There are several peri-urban areas within the territory of Novi Sad where urban development had a negative effect on spatial planning and sustainable development of the city. The major problems in these areas include illegal building work, lack of standards, noncompliance with plans, and absence of traffic and communal infrastructure. The most difficult situation, however, can be seen in those areas where unplanned urbanisation lead to unsafe living conditions for people who live in those areas.

The southern part of the city of Novi Sad called Kamenjar is potentially the most unsafe and the most endangered part of the city due to its unplanned urbanisation and its position close to the river Danube. The settlement was erected in the Danube floodplain, between the river and the embankment (see Fig. 1). As such, it is an unprotected area when flood risk is concerned.

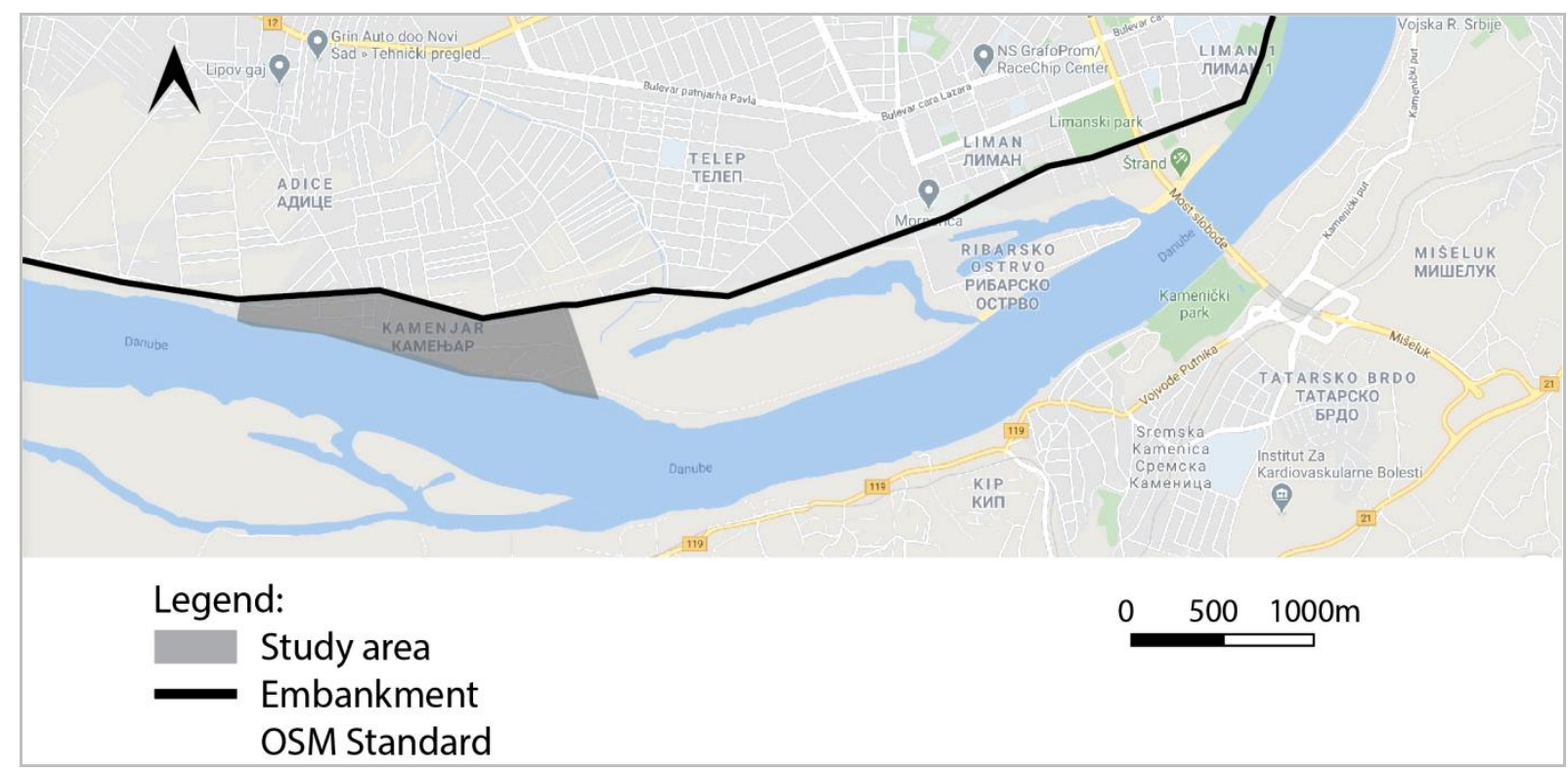

Figure 1: Spatial context of the suburban zone.

Illegal urbanisation in this part of the city began in the 1990s. So far, almost four hundred buildings with different purposes have been built. In the beginning, the buildings were intended to serve as holiday homes. However, as a result of the urban expansion and merging of the city with the suburban settlement of Veternik, this part of the city has become a predominantly residential area with permanent family dwellings.

As an undefended area, this part of the city is particularly vulnerable to floods and changes in the water level. In disaster-affected areas, emergency relief supplies have to be delivered in the shortest time [13]. Since the whole settlement was built illegally, the local authorities do not bear any responsibility in case of risk realisation. The responsibility rests solely with the inhabitants. The transfer of risk to insurance companies is not available to people in this part of the city either. High exposure to risk and illegal property are not acceptable to insurers.

However, over the past few years, a certain number of properties have been legalised and registered as holiday homes. This has opened up a possibility for ex ante financing and transferring part of the risk to the insurers if the insurers would be willing to reconsider the possibilities of insuring such properties and define the acceptable level of risk. 


\section{DATA AND METHODOLOGY}

\subsection{GoT based flood risk insurance modelling}

The convenience of a methodological and technological framework for the exchange of methods and data was recognised by Kamilaris and Ostermann [14]. They put the concepts of "Internet of Things", "Pervasive Computing", "Geospatial Analysis", "Data Mining", and "Geographical Information Systems" into the common context, facilitating adequate risk analysis in urban and suburban zones.

Hydrotechnical measures have long been seen as the basic instrument for the reduction of vulnerability to floods. However, the contemporary holistic approach to risk management, apart from adequate hydrotechnical measures, emphasises the financial resilience of a social community as the key component of efficient reduction of vulnerability to extreme weather $[15,16]$.

The most frequently used parameter for describing direct tangible damage is the depth of flooding [17]. Associated with land use [18], depth-damage functions have become the standard approach in flood damage or impact assessment [19]. Using the historical data on the water level of the Danube in Novi Sad in the last five years, a simulation of the flood wave which endangered the observed area was run.

Depending on the frequency of flooding, five simulations were run by means of Quantum GIS software. Quantum GIS is a free and open-source cross-platform desktop Geographic Information System (GIS) application that supports viewing, editing, and analysis of geospatial data [20]. GIS can interpret the real world by layering and integrating information based on geographic location [21]. It can describe a community in multi-scale, space-time dimensions with detailed information in the attribute table [21]. Unlike with data in conventional information systems, the data in geographic information systems do not contain only thematic or temporal features, but they contain an additional spatial component, too. Thus, if GIS is observed in the organisational sense, it can be said that GIS encompasses integration of spatially referenced data in an area, making the decision-making process easier and smarter [22, 23]. GIS technologies have created more favourable conditions for the creation and representation of terrain [24], i.e., a modern method of presenting spatial data and land surface, the so-called digital elevation model.

After completing the simulations, it is necessary to put the data on the flooded properties into the context of flood risk insurance (GoT) in order to obtain information about the price of risk in the endangered area, which is necessary for further decision-making and smart city management.

Access to data on the characteristics of property that is the subject of insurance, its location, and the organisation of these data form the basis for sustainable and efficient business activity of insurance companies. Namely, the insurers cannot fully perceive nor understand risks that potential customers are exposed to until they have data on their exact location, i.e., until those data are placed into the spatial context.

Spatial data such as the location of the property being insured and its nearness or distance from the potential source of danger are crucially important in the assessment of risk that an insurance company accepts. The use of GIS technologies in the analysis and assessment of risk contributes to higher accuracy of predictions and understanding of topological relations between the given location and other spatial data such as flood zones.

\subsection{Insurance premium rate}

Flood, flash flood and high water insurance, under the current conditions of insurers in the Republic of Serbia, is an additional insurance which can be arranged together with fire 
insurance and can only be arranged if fire insurance has already been purchased. This way the insurers atomise flood risk and disperse it in space and time. The reason for this is great correlation risk that flooding entails.

Premium rates for the insurance against flood, flash flood and high water risk are determined depending on classes of danger. When determining classes of danger, i.e., the exposure of an area or property to flood, flash flood and high water risk, what needs to be considered is the terrain, the topographical location, the probability and frequency of flooding. The basis for determining flood prone areas can be smaller or larger areas depending on the hazard, i.e., exposure of the area to floods and flash floods.

\section{RESULTS}

The simulation of the flood wave propagation for each of the defined probabilities of occurrence was performed by means of Quantum GIS software (QGIS). The input necessary for the simulation is the digital elevation model (DEM) of the territory of Novi Sad and of the suburban zone of Kamenjar. Furthermore, it is neceessary to load the map of this zone by means of OpenLayers plugin. The DEM, as an organised set of data, enables acquiring data about the position and height of any point of the terrain. The reference coordinate system used in importing the DEM into QGIS was MGI 1901/Balkans zone 7.

Entering the commands for the display of parts of the terrain which are lower than the typical water levels observed in the five-year period, five vector layers of the flood wave propagation were created. The resulting polygons are the first input data for the spatial analysis of the exposure of properties to potential floods. The second piece of input data is the vector layer which shows the properties in the observed zone, created using the point geometry. By overlaying the vector layer of properties with flood vectors characterised by typical water levels, it was determined which properties were exposed to potential danger of flood whose probability of occurrence corresponds to the classes of danger of the insurer.

Classes of danger for the property that is being insured are determined for each calendar year based on the frequency of flooding. Premium rates are in proportion to classes of danger, i.e., the greater the danger, the higher the insurance premium rate. The plan for the performed simulations was made in accordance with these.

For the purpose of this research, the analysis included 398 properties exposed to flood risk. It was assumed that the average size of properties in the obsereved area was $100 \mathrm{~m}^{2}$ and that the average price of building was $750 € / \mathrm{m}^{2}$. This way the average building value of a property was obtained, the value that the insurer uses to calculate the insurance price. The simulation of flood frequency shows classes of danger that the insurer considers when evaluating risk.

The first scenario shows the least favourable class (the highest premium rate), whereas the last scenario corresponds to the most favourable class of danger. When premium rates which correspond to the analysed classes of flood danger are applied to the average value of property, the cost of risk acceptable to the insurer is calculated, but also the total value of the property that the insurer is ready to underwrite according to the observed scenarios. The following table shows the input data for simulation of the flood waves which endangered the observed area as well as for the average property value calculation. 
Table I: Input data for simulation of the flood waves and calculation of the endangered properties value.

\begin{tabular}{|c|c|c|c|}
\hline Variable & Value & Unit & Source \\
\hline Elevation of terrain & $73-82$ & $\begin{array}{c}\mathrm{m} \text { above } \\
\text { sea level }\end{array}$ & Digital elevation model \\
\hline Water levels & $75.24-76.56$ & $\mathrm{~m}$ & $\begin{array}{c}\text { Republic Hydrometeorological } \\
\text { Service of Serbia }\end{array}$ \\
\hline $\begin{array}{c}\text { Average size } \\
\text { of property }\end{array}$ & 100 & $\mathrm{~m}^{2}$ & Interview \\
\hline $\begin{array}{c}\text { Average price } \\
\text { of property }\end{array}$ & 750 & $\mathrm{EUR} / \mathrm{m}^{2}$ & Interview \\
\hline
\end{tabular}

GIS enables determining the price of risk which is equivalent to the level of risk, as expected damage to structure is strongly related to floodwater depth [16].

This section of the paper shows the results of five flood simulations in the observed area with different floodwater depths, which correspond to the previously mentioned classes of danger.

Simulation 1 - the area in the last five years, 1 year without flooding. The characteristic value of water level in this simulation is $75.24 \mathrm{~m}$ above sea level. Under this scenario, i.e., with this frequency of flooding, 97 properties out of 398 were flooded four times in the last five years (in one year they were not flooded), whereas 301 properties were flooded all five times (see Fig. 2). Under the current conditions of insurers and based on the results of the simulation, only $24.37 \%$ of properties could be insured against flood risk, whereas $75.63 \%$ of properties would be unacceptable for insurance.

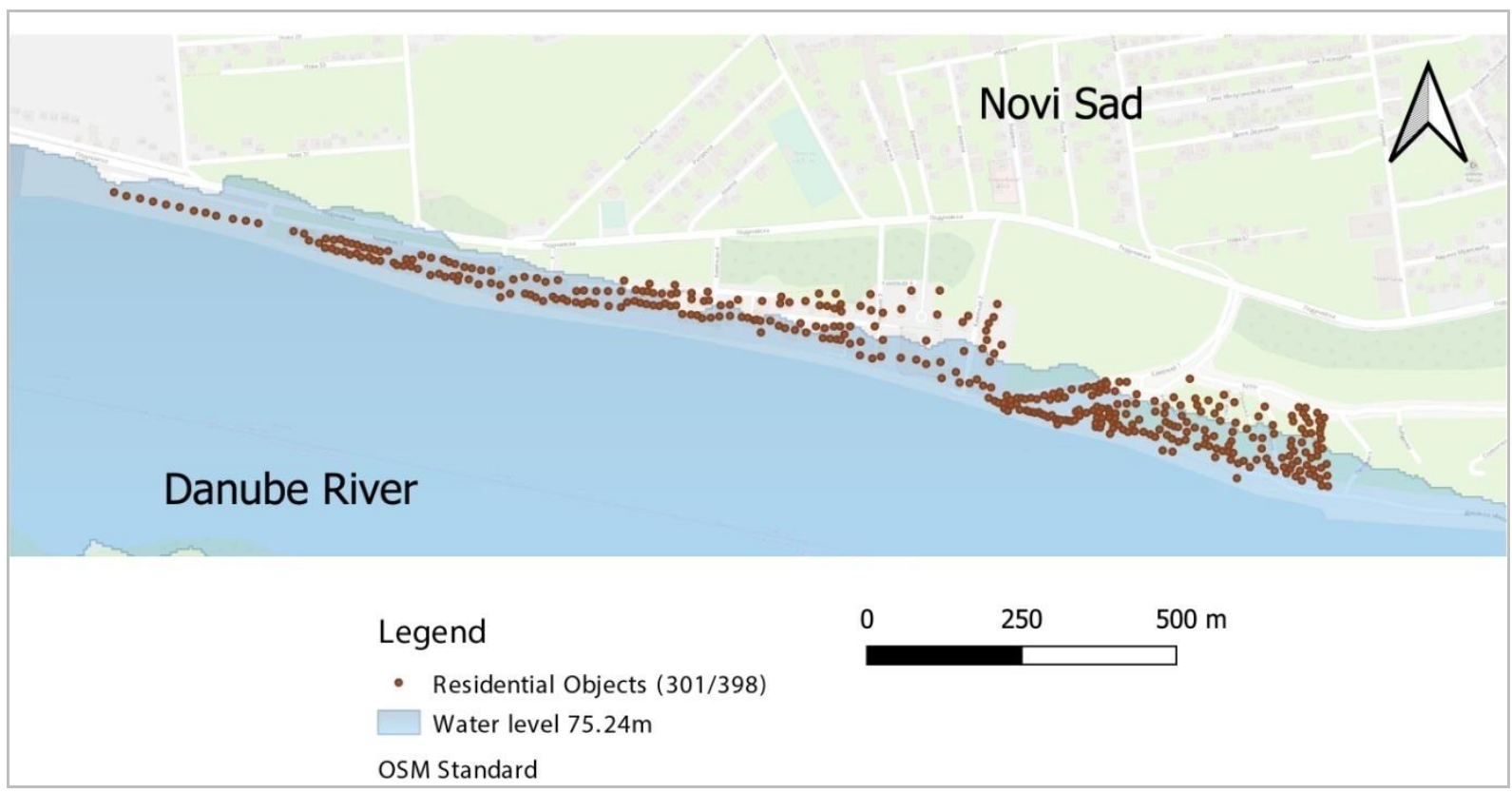

Figure 2: Simulation 1.

Simulation 2 - the area in the last five years, 2 years without flooding. The characteristic value of water level in this simulation is $75.92 \mathrm{~m}$ above sea level. Under this scenario, i.e, with this frequency of flooding, 76 properties out of 398 were flooded three times in the last five years (two years without flooding), whereas 322 properties were flooded more frequently (see Fig. 3). Under the current conditions of insurers and based on the results of the 
simulation, only $19.10 \%$ of properties could be insured against flood risk, whereas $80.90 \%$ of properties would be unacceptable for insurance.

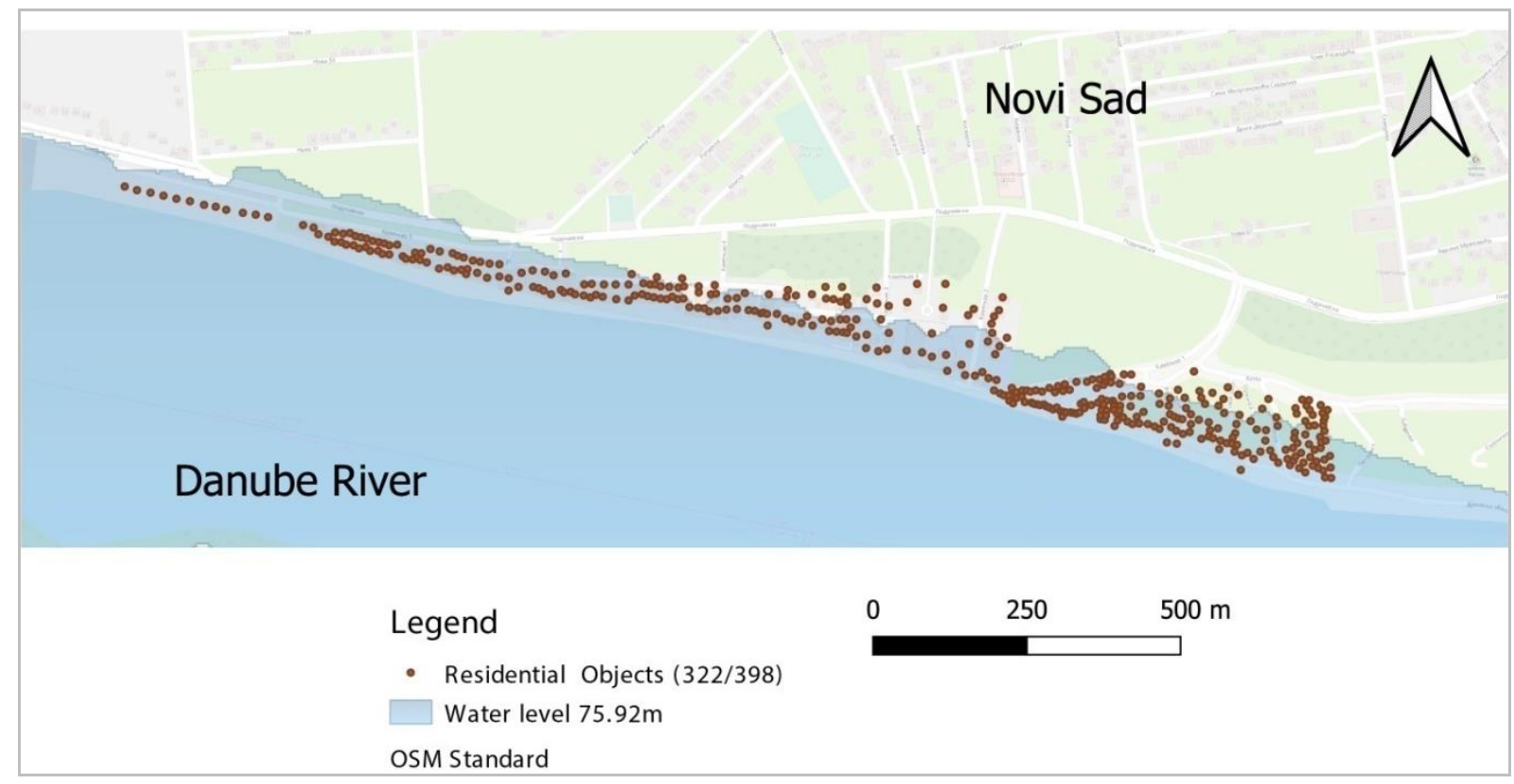

Figure 3: Simulation 2.

Simulation 3 - the area in the last five years, 3 years without flooding. The characteristic value of water level in this simulation is $76.19 \mathrm{~m}$ above sea level. Under this scenario, i.e., with this frequency of flooding, 65 properties out of 398 were flooded twice in the last five years (three years without flooding), whereas 333 properties were flooded more frequently (see Fig. 4). Under the current conditions of insurers and based on the results of the simulation, only $16.33 \%$ of properties could be insured against flood risk, whereas $83.67 \%$ of properties would be unacceptable for insurance.

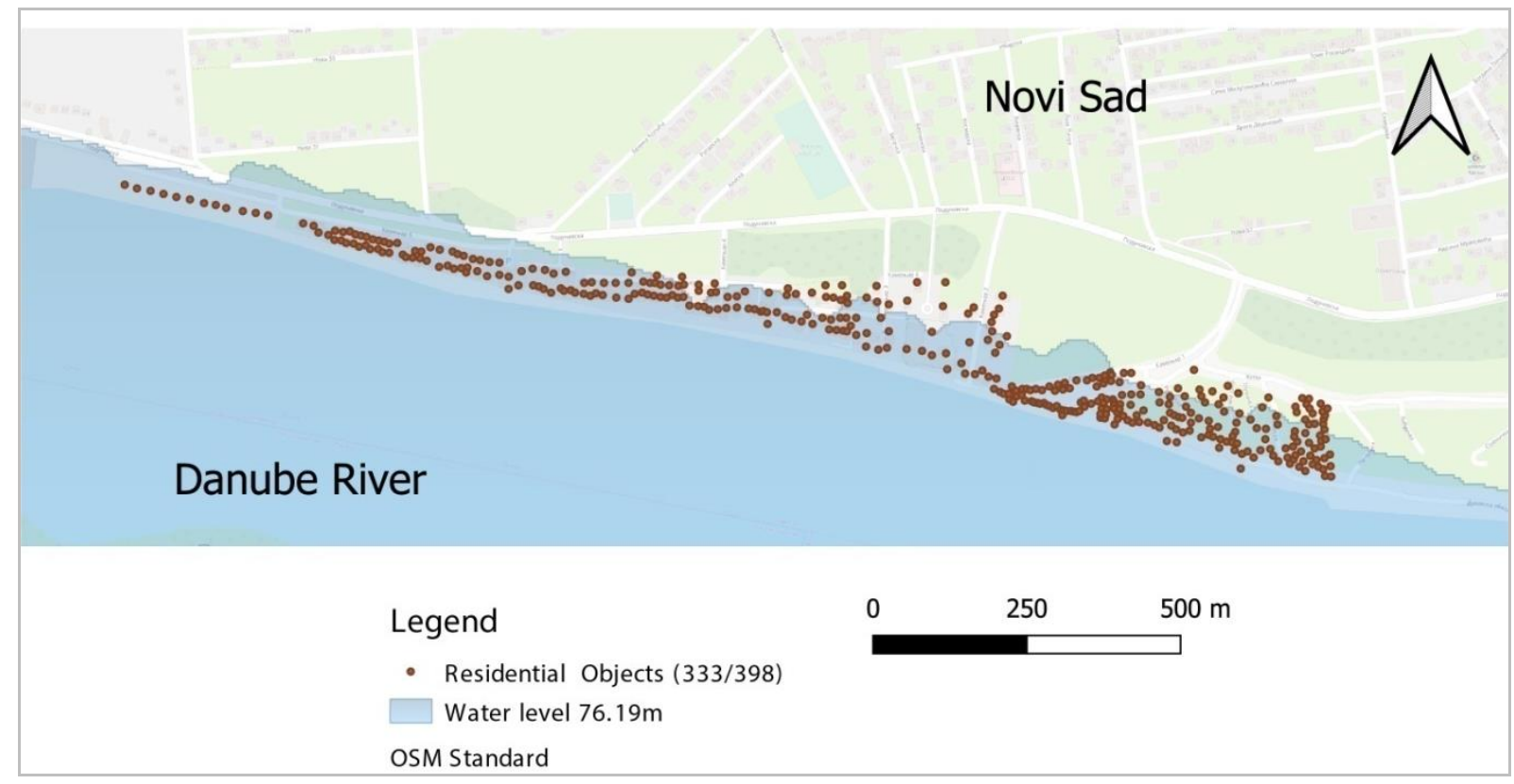

Figure 4: Simulation 3.

Simulation 4 - the area in the last five years, 4 years without flooding. The characteristic value of water level in this simulation is $76.34 \mathrm{~m}$ above sea level. With flood frequency of 
only once in five years, the simulation showed that 55 properties out of 398 were flooded once in the last five years ( four years without flooding), whereas 343 properties were flooded more frequently (see Fig. 5). Under the current conditions of insurers and based on the results of the simulation, only $13.82 \%$ of properties could be insured against flood risk, whereas $86.18 \%$ of properties would be unacceptable for insurance.

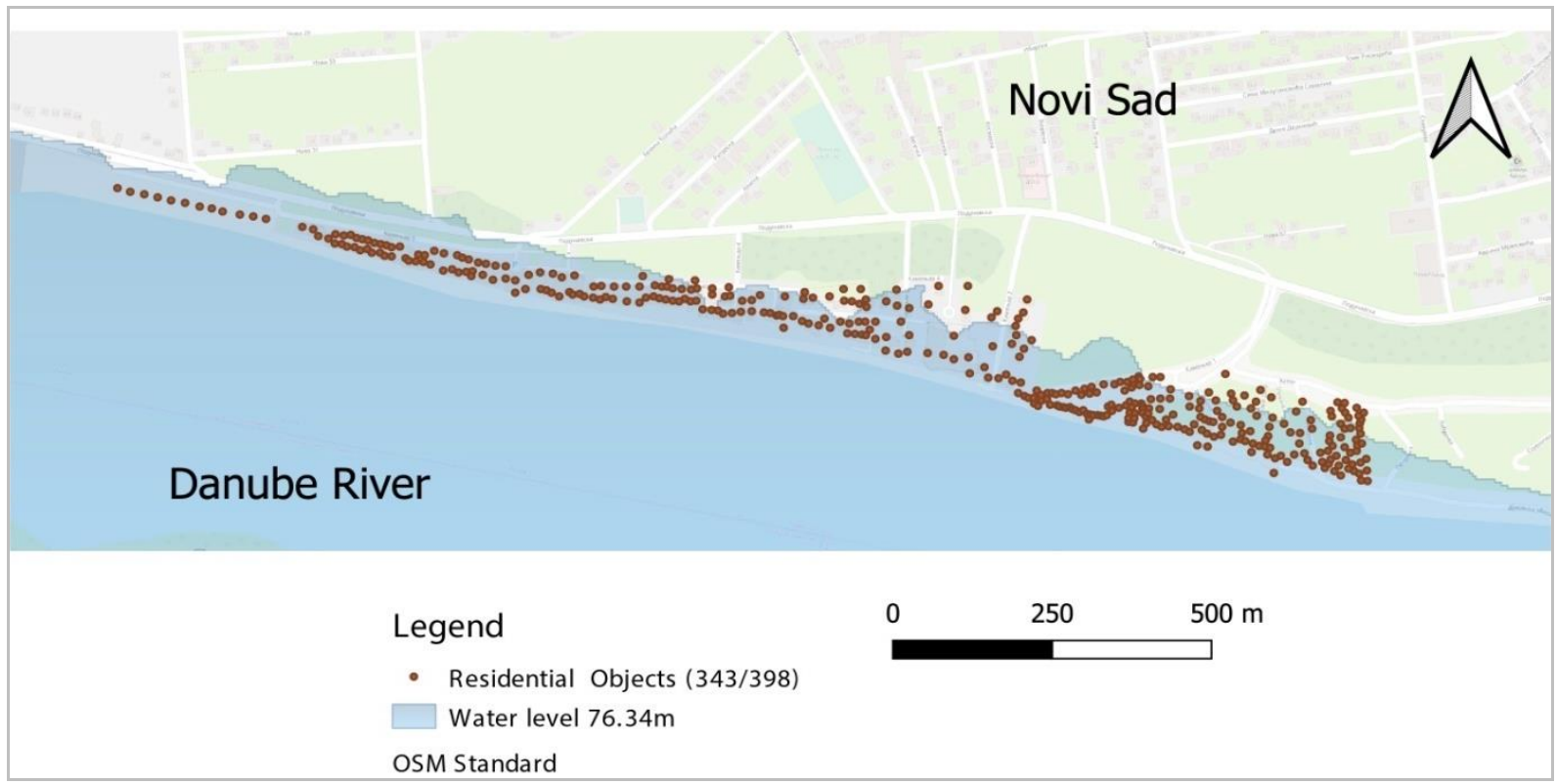

Figure 5: Simulation 4.

Simulation 5 - the area was not flooded in the last five years. The characteristic value of water level in this simulation is $76.56 \mathrm{~m}$ above sea level. Simulating the highest flood wave in the last five years, it was determined that only 45 properties out of 398 were not flooded at all in the last five years, whereas 353 properties were flooded (see Fig. 6). Under the current conditions of insurers and based on the results of the simulation, only $11.31 \%$ of properties could be insured against flood risk, whereas $88.69 \%$ of properties would be unacceptable for insurance.

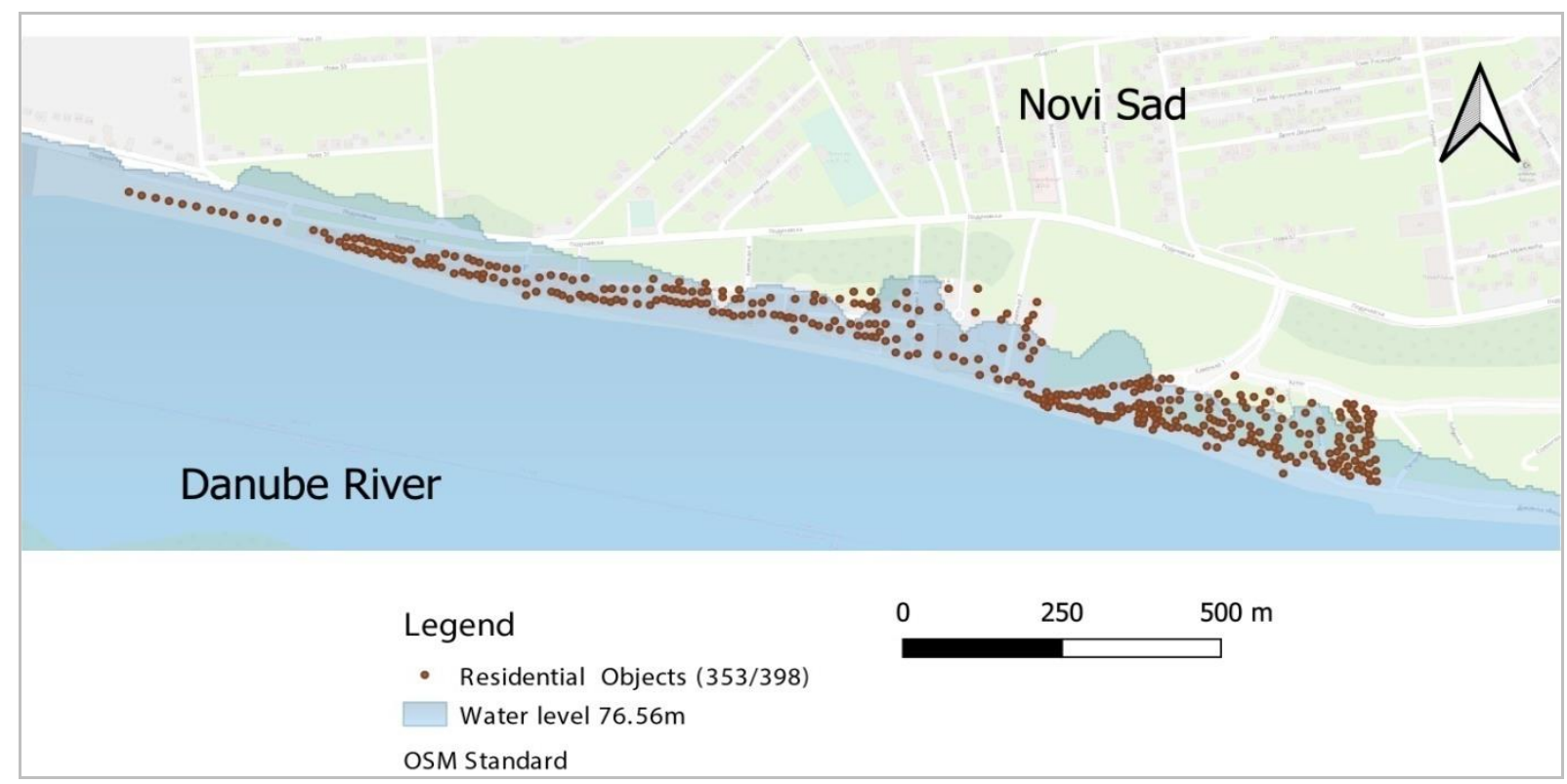

Figure 6: Simulation 5. 
If risk is quantified via the probability of a harmful event (flood frequency) and its harmful consequences (the expected amount of damage), the simulation results show that flood risk in the observed area is high and that the properties are exposed to great danger. As it was already mentioned, this area is not protected against floods and the majority of its inhabitants have settled here permanently. This means that the social vulnerability of this area is extremely high. Since social vulnerability is closely connected with economic vulnerability, it is necessary to evaluate the economic vulnerability of the observed area in the sense of capital value exposed to risk. Assessing the part of risk which is convenient for financing and transferring to the insurer makes it possible to find the most suitable risk management model which contributes to the Smart City concept. The following table shows the results of the simulations and the degree of risk which is acceptable to the insurer.

Table II: Acceptable and unacceptable risk for insurance underwriting.

\begin{tabular}{|c|c|c|c|c|c|c|c|c|}
\hline \multirow[b]{2}{*}{ 苛 } & \multicolumn{3}{|c|}{ Flooded properties } & \multicolumn{5}{|c|}{ Unflooded properties } \\
\hline & No & $\%$ & $\begin{array}{l}\text { Unacceptable } \\
\text { risk in EUR }\end{array}$ & No & $\%$ & $\begin{array}{c}\text { Annual } \\
\text { insurance } \\
\text { premium per } \\
\text { property in } \\
\text { EUR }\end{array}$ & $\begin{array}{l}\text { Total annual } \\
\text { insurance } \\
\text { premium in } \\
\text { EUR }\end{array}$ & $\begin{array}{l}\text { Acceptable } \\
\text { risk in EUR }\end{array}$ \\
\hline 1 & 301 & 75.63 & $22,575,000.00$ & 97 & 24.37 & 933 & $90,501.00$ & $7,275,000.00$ \\
\hline 2 & 322 & 80.90 & $24,150,000.00$ & 76 & 19.10 & 678 & $51,528.00$ & $5,700,000.00$ \\
\hline 3 & 333 & 83.67 & $24,975,000.00$ & 65 & 16.33 & 509 & $33,052.50$ & $4,875,000.00$ \\
\hline 4 & 343 & 86.18 & $25,725,000.00$ & 55 & 13.82 & 297 & $16,335.00$ & $4,125,000.00$ \\
\hline 5 & 353 & 88.69 & $26,475,000.00$ & 45 & 11.31 & 131 & $5,872.50$ & $3,375,000.00$ \\
\hline
\end{tabular}

It can be concluded that only a very small percentage of risk in the analysed area is economically acceptable to the insurer under the current conditions and premium rates. Apart from limited insurance coverage, for some classes of danger coverage is even financially unacceptable when the whole socioeconomic capacity of the society is considered. Therefore, the insurers should change insurance conditions and offer different insurance models for structures with more than one floor. Partial insurance of upper floors would enable partial coverage. With such a model, more properties would be acceptable to insurers in all the simulated classes of danger (scenarios), especially in those which are more financially acceptable to potential insurers.

Modelling and simulation of different scenarios resulted in GoT based flood risk insurance model which combines the social community, built environment, IoT sensor systems, series of the existing data, public utilities and economic services, and potential hazard in the spatial context of the modern Smart Community (see Fig. 7). 


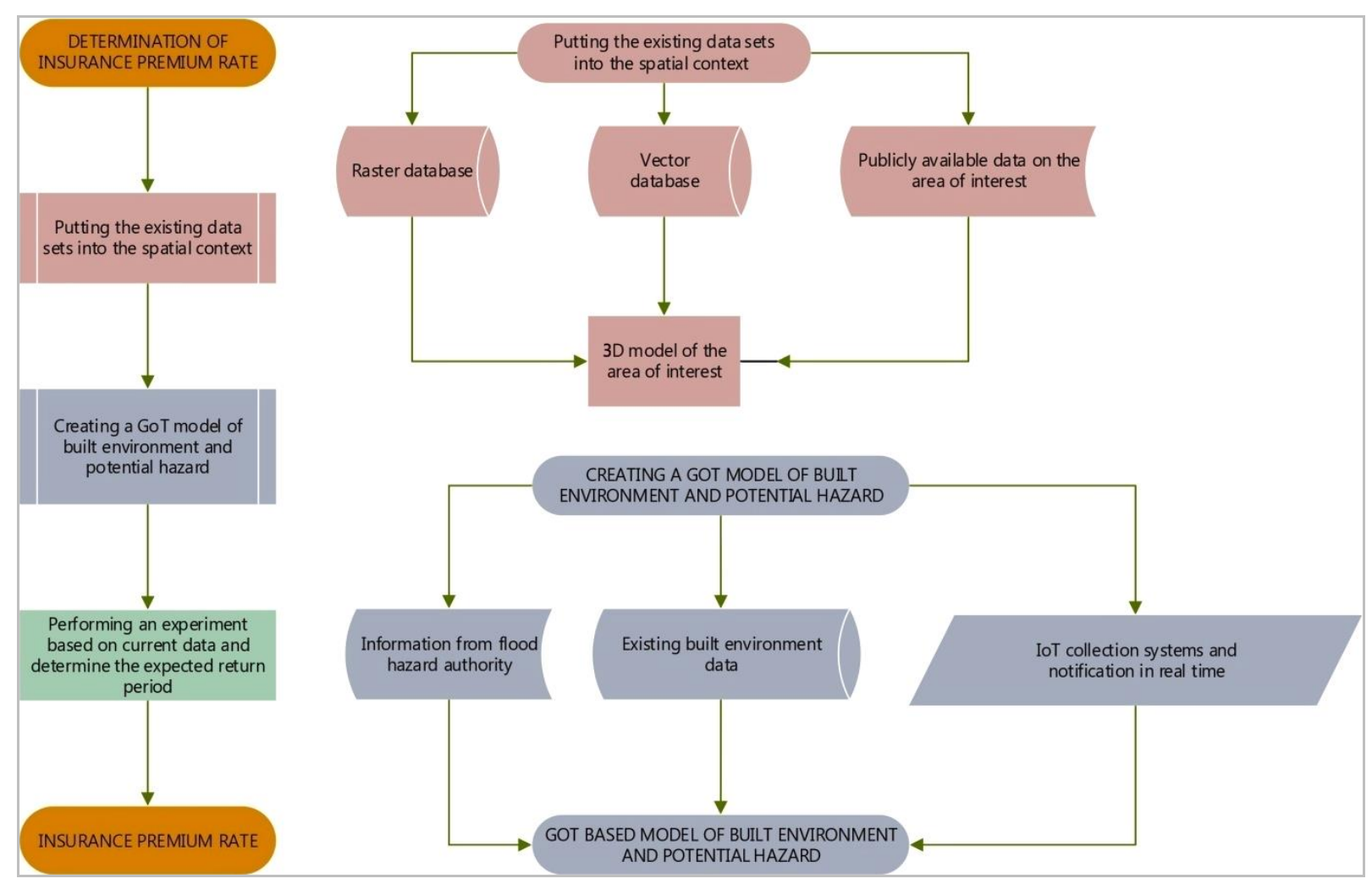

Figure 7: Proposed model - GoT based flood risk insurance model.

\section{CONCLUSIONS AND FURTHER WORK}

The focus of the paper was on assessing the part of risk that is convenient for financing, transferring it to the insurer and finding the most suitable model for risk management which also contributes to the Smart City concept. The reason for this study was the identified social and infrastructural vulnerability of some parts of Novi Sad. There are several peri-urban areas of the city where urban growth had a negative effect on spatial planning and sustainable development of the city. The area chosen for the study is only $5 \mathrm{~km}$ from the highly urbanised zone.

With the approach that is based on the Smart City concept and GoT technologies, in its simplest implementation, we combined: information from flood hazard authority, the existing built environment data, IoT collection systems and notification in real time. This way we created a model which enabled us to formulate spatial queries and perform an experiment based on current data and determine the expected return period. Based on the results, the insurance premium rates were calculated.

The calculations showed that the premium rates of the insurers are high and so is the cost of flood insurance. Since exposure to risks in today's world is high and natural disasters are on the increase, it is necessary to modify insurance conditions and expand coverage (flat rates are applied now). With the today's traditional approach to risk assessment, the degree to which coverage could be expanded can only be determined after many years of risk observation. In the circumstances of high weather variability and risk irregularity this is unacceptable both to the insurer and in the marketplace. The use of the GoT model we created and presented in this paper enables collection and analysis of a large volume of data sets in real time which helps in discovering useful hidden patterns and other information. From the results of the research it can be concluded that the traditional approach to the insurance risk assessment can be improved and digitalised by developing a system for data collection in real time, simulation of natural hazards and modelling insurance conditions. The proposed model 
makes it possible to evaluate risk in a short period of time, with greater accuracy and precision than the current approach.

For an urban zone to be characterised as a Smart City it is necessary to create Digital Twins of buildings and infrastructure. The presented digital model of the endangered area is an adequate basis for the creation of a Spatial Digital Twin of the observed area. Spatial Digital Twin is a part of digital government. It has unlimited possibilities of collecting and storing data about real surroundings, creating a virtual surrounding in which it is possible to simulate, model and evaluate potential risk, all of which is very important for sucessful business and economy.

A larger number of GoT based data sources in the urban and peri-urban areas of Novi Sad would increase the resolution of the decision-making model. Recognition and acquisition of new kinds of data would enhance the process of observing other risks such as fire risk, hazardous material spill and leak risk, extreme weather risk, etc.

There are many sensor networks in Novi Sad. However, no system performs action in real time although the GoT concept offers that possibility. There is a number of risks that need to be recognised and explained through data analysis. Processing of the acquired data can be easily modelled, developed and, when necessary, upgraded.

\section{REFERENCES}

[1] United Nations, Department of Economic and Social Affairs, Population Division World. Urbanization Prospects: The 2018 Revision (ST/ESA/SER.A/420), from https://population.un.org/wup/Publications/Files/WUP2018-Methodology.pdf/, accessed on 1501-2020

[2] United Nations, Department of Economic and Social Affairs, Population Division World. Transforming our world: the 2030 Agenda for Sustainable Development (A/RES/70/1), from https://sustainabledevelopment.un.org/post2015/transformingourworld/, accessed on 15-01-2020

[3] Popov, S. (2019). SMART City - GIS and IoT integration, Proceedings of the AIIT 2019, 24-28

[4] Chamoso, P.; González-Briones, A.; De La Prieta, F.; Venyagamoorthy, G. K.; Corchado, J. M. (2020). Smart city as a distributed platform: Toward a system for citizen-oriented management, Computer Communications, Vol. 152, 323-332, doi:10.1016/j.comcom.2020.01.059

[5] Dingfu, J. (2020). The construction of smart city information system based on the Internet of Things and cloud computing, Computer Communications, Vol. 150, 158-166, doi:10.1016/j.comcom.2019.10.035

[6] Bresciani, S.; Ferraris, A.; Del Giudice, M. (2018). The management of organizational ambidexterity through alliances in a new context of analysis: Internet of Things (IoT) smart city projects, Technological Forecasting and Social Change, Vol. 136, 331-338, doi:10.1016/j.techfore.2017.03.002

[7] Gupta, A.; Panagiotopoulos, P.; Bowen, F. (2020). An orchestration approach to smart city data ecosystems, Technological Forecasting and Social Change, Vol. 153, Paper 119929, doi:10.1016/j.techfore.2020.119929

[8] García, C. G.; Núñez-Valdez, E. R.; García-Díaz, V.; Bustelo, B. C. P. G.; Lovelle, J. M. C. (2018). A review of artificial intelligence in the internet of things, International Journal of Interactive Multimedia and Artificial Intelligence, Vol. 5, No. 4, 9-20, doi:10.9781/ijimai.2018.03.004

[9] Safiullin, A.; Krasnyuk, L.; Kapelyuk, Z. (2019). Integration of Industry 4.0 technologies for "smart cities" development, IOP Conference Series: Materials Science and Engineering, Vol. 497, Paper 012089, doi:10.1088/1757-899X/497/1/012089

[10] Vieira, A. A. C.; Dias, L. M. S.; Santos, M. Y.; Pereira, G. A. B.; Oliveira, J. A. (2018). Setting an Industry 4.0 research and development agenda for simulation - a literature review, International Journal of Simulation Modelling, Vol. 17, No. 3, 377-390, doi:10.2507/ $\underline{\operatorname{IJSIMM} 17(3) 429}$ 
[11] Lom, M.; Pribyl, O.; Svitek, M. (2016). Industry 4.0 as a part of smart cities, Smart Cities Symposium Prague (SCSP), 6 pages, doi:10.1109/SCSP.2016.7501015

[12] Janekova, J.; Fabianova, J.; Fabian, M. (2019). Assessment of economic efficiency and risk of the project using simulation, International Journal of Simulation Modelling, Vol. 18, No. 2, 242 253, doi:10.2507/IJSIMM18(2)467

[13] Zeng, J.; Yao, Q. G.; Zhang, Y. S.; Lu, J. T.; Wang, M. (2019). Optimal path selection for emergency relief supplies after mine disasters, International Journal of Simulation Modelling, Vol. 18, No. 3, 476-487, doi:10.2507/IJSIMM18(3)486

[14] Kamilaris, A.; Ostermann, F. O. (2018). Geospatial analysis and the internet of things, International Journal of Geo-Information, Vol. 7, No. 7, Paper 269, doi:10.3390/ijgi7070269

[15] United Nations, United Nations Office for Disaster Risk Reduction. Sendai Framework for Disaster Risk Reduction 2015 - 2030, from https://www.undrr.org/publication/sendaiframework-disaster-risk-reduction-2015-2030/, accessed on 15-01-2020

[16] Cosic, D.; Popov, S.; Novakovic, T.; Popovic, L. (2019). Flood damage assessment method: GIS based approach, Fresenius Environmental Bulletin, Vol. 28, No. 3, 1896-1904

[17] Gerl, T.; Kreibich, H.; Franco, G.; Marechal, D.; Schröter, K. (2016). A review of flood loss models as basis for harmonization and benchmarking, PLoS ONE, Vol. 11, No. 7, Paper e0159791, 22 pages, doi:10.1371/journal.pone.0159791

[18] White, G. F. (1964). Choice of adjustments to floods (Research Paper No. 93), Department of Geography, University of Chicago, Chicago

[19] Smith, D. I. (1994). Flood damage estimation - a review of urban stage-damage curves and loss functions, Water SA, Vol. 20, No. 3, 231-238

[20] QGIS. Quantum GIS - Open Source Geographic Information System Software, from https://www.qgis.org/en/site/about/index.html/, accessed on 15-01-2020

[21] Yamamura, S.; Fan, L.; Suzuki, Y. (2017). Assessment of urban energy performance through integration of BIM and GIS for smart city planning, Procedia Engineering, Vol. 180, 1462-1472, doi:10.1016/j.proeng.2017.04.309

[22] Cowen, D. J.(1988). GIS versus CAD versus DBMS: what are the differences?, Photogrammetric Engineering and Remote Sensing, Vol. 54, No. 11, 1551-1555

[23] Smith, T. R.; Menon, S.; Starr, J. L.; Estes, J. E. (1987). Requirements and principles for the implementation and construction of large-scale geographic information systems, International Journal of Geographical Information Systems, Vol. 1, No. 1, 13-31, doi:10.1080/ $\underline{02693798708927790}$

[24] Burrough, P. A.; McDonnell, R. A. (1998). Principles of Geographical Information Systems, $2^{\text {nd }}$ edition, Oxford University Press, Oxford 